\title{
Misdiagnosed paranasal gossypiboma: a 10-year experience with 21 cases at a tertiary center*
} Department of Otorhinolaryngology, The First Affiliated Hospital, Otorhinolaryngology Institute, Sun Yat-sen University, Guangzhou, People's Republic of China
Rhinology 55: 281-287, 2017

https://doi.org/10.4193/Rhino16.341

*Received for publication:

December 31, 2016

Accepted: March 10, 2017

\# Both authors contributed equally to this work

\begin{abstract}
Background: Different from rhinoliths, the paranasal gossypiboma is a foreign body, such as a surgical sponge, left in the nasal cavity. It is a rare, frequently misdiagnosed disease that has rarely been reported. We summarize its clinical characteristics, management, and possible risk factors.

Methodology: We reviewed medical records of confirmed paranasal gossypibomas at a tertiary medical center between 2005 and 2015. Clinical symptoms, age, sex, anatomic sites, endoscopic photography, computed tomography, intraoperative findings, and past medical history were reviewed.

Results: The study included 21 patients, each of whom had ultimately undergone two operations. Among them, 20 underwent endoscopic nasal surgery in primary hospitals, and 15 had been misdiagnosed during the second surgery. The average interval to discovery of a retained foreign body was 200 days. Predominant occurrence sites were the maxillary and ethmoid sinuses. Computed tomography showed paranasal gossypiboma as a heterogeneous cystic lesion with a thin "calcified shell."
\end{abstract}

Conclusions: A history of endoscopic nasal surgery, especially performed at a primary hospital, is a warning sign for clinicians. Computed tomography can add to the warning by showing a heterogeneous cystic lesion with a thin "calcified shell." Clinicians should be aware of these characteristics to avoid misdiagnosing paranasal gossypiboma.

Key words: foreign body, paranasal sinus, nasal surgery, endoscopic surgery, diagnosis

\section{Introduction}

Gossypiboma is a cotton matrix mass in the body that is usually a retained surgical gauze or sponge surrounded by a foreign body reaction ${ }^{(1)}$. Although some studies have reported the clinical manifestation of gossypiboma in other body cavities (e.g., thorax, abdomen), the characteristics of paranasal gossypiboma remain unclear ${ }^{(2,3)}$. Because of its non-specific clinical and radiological manifestation, it can be misdiagnosed easily as another paranasal disease. After reviewing 21 paranasal gossypiboma cases that occurred over the past decade, we report the clinical features, radiologic characteristics, and treatment results. Our aim is to help ENT surgeons diagnose paranasal gossypiboma accurately.

\section{Materials and methods}

We reviewed the medical records of 21 patients with confirmed paranasal gossypiboma admitted through the Otorhinolaryngology and Head and Neck Department in Sun Yat-sen First Affiliated Hospital from January 1, 2005, to November 19, 2015. We collected information, when available, regarding their sex, age, 


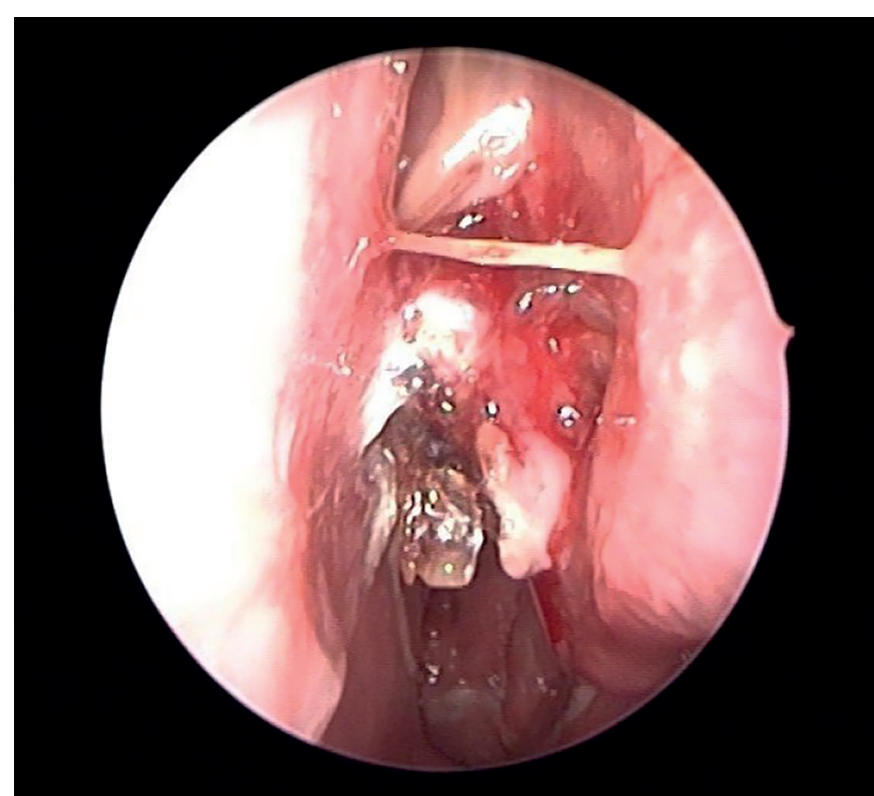

Figure 1A

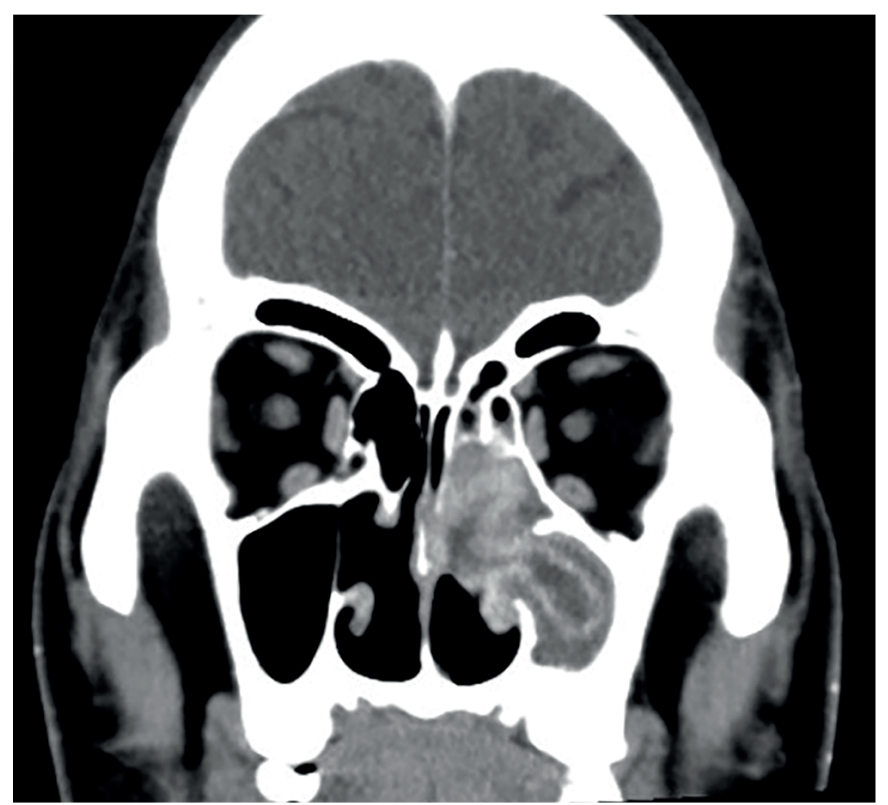

Figure 1C

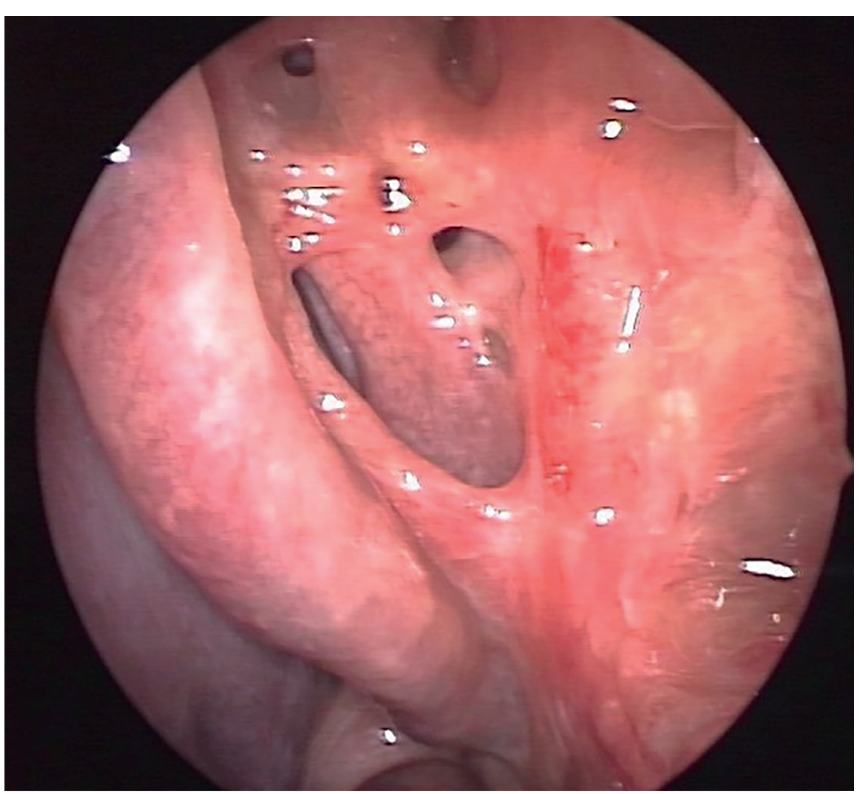

Figure 1B

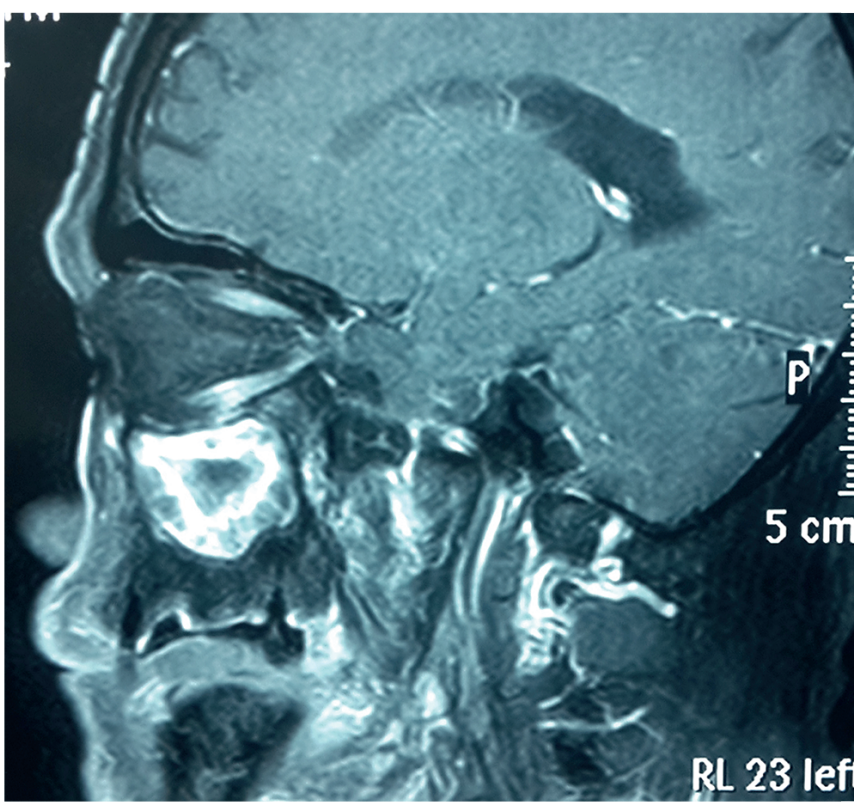

Figure 1D

Figure 1. Nasal endoscopy and paranasal imaging of case 6. A. Preoperative endoscopic examination. Blood and a pus-stained, granular-like, reddish mass on the left middle meatus. B. Endoscopy at 3 weeks postoperatively shows full recovery. C. Coronal computed tomography shows a single, wellcircumscribed mass with internal heterogeneous density and a "calcified shell" occupying the left maxillary sinus and left middle meatus. Note the bone deficiency on the left maxillary sinus, middle meatus, and ethmoid sinus due to prior nasal surgery. D. Sagittal magnetic resonance imaging of the patient. T1-enhanced image shows irregular intermediate signal intensity with capsular enhancement in the left maxillary sinus.

body mass index, primary complaints, clinical symptoms, presentations, lesion sites, endoscopic imaging, radiology results, and past nasal surgery and dental procedure histories (Table 1).

Among a total of 5778 patients who underwent endoscopic surgery from 2005 to 2015 , the incidence of gossypiboma was $0.36 \%$. The patients' average age was 35 years [range $1-75$ (SD
16) years]. There were 11 men and 10 women. Their average body mass index was $20 \mathrm{~kg} / \mathrm{m}^{2}$ [range 17-23 (SD 2.1) kg/m²).

The follow-up period ranged from 2 to 117 months [mean 52 (SD 37.5) months]. All data analyses were performed using SPSS 22.0 software (SPSS, Chicago, IL, USA). A value of $\mathrm{P}<0.01$ was considered to indicate significance. 
Table 1. Clinical data for 21 patients diagnosed with paranasal gossypiboma

\begin{tabular}{|c|c|c|c|c|c|c|c|c|c|c|}
\hline Case & $\begin{array}{l}\text { Op } \\
\text { year }\end{array}$ & $\begin{array}{l}\text { Fo. Up } \\
\text { (mos) }\end{array}$ & $\begin{array}{l}\text { Age/ } \\
\text { Sex }\end{array}$ & $\begin{array}{c}\text { Site } \\
\text { (sinus) }\end{array}$ & Dental P. & Past History & $\begin{array}{l}\text { Endoscopic } \\
\text { findings }\end{array}$ & Op & $\begin{array}{c}\text { Initial } \\
\text { Diagnosis }\end{array}$ & $\begin{array}{l}\text { Foreign } \\
\text { body }\end{array}$ \\
\hline 1 & 2010 & 72 & $39 / F$ & $R(S p)$ & no & $\begin{array}{l}\text { Endoscopic chordoma resection } \\
4 \text { mos prior }\end{array}$ & Re,Ir & ESS & $\begin{array}{l}\text { Nasal septum } \\
\text { mass }\end{array}$ & ADM \\
\hline 2 & 2015 & 11 & $45 / F$ & $R(M)$ & $\begin{array}{l}\text { Tooth } \\
\text { Blea- } \\
\text { ching }\end{array}$ & $\begin{array}{l}\text { Endoscopic Septoplasty and } \\
\text { rhinoplasty } 6 \text { mos prior }\end{array}$ & $\mathrm{Re}, \mathrm{Ir}, \mathrm{Gr}, \mathrm{Ps}$ & ESS & Paranasal mass & ES \\
\hline 3 & 2012 & 38 & $44 / F$ & $R(E)$ & no & $\begin{array}{c}\text { Endoscopic removal of NPs } 6 \\
\text { mos prior }\end{array}$ & $\mathrm{Re}, \mathrm{Gr}, \mathrm{Ps}$ & ESS & $\begin{array}{l}\text { Paranasal } \\
\text { foreign body }\end{array}$ & $\mathrm{CP}$ \\
\hline 4 & 2009 & 53 & $40 / F$ & $R(M)$ & Den. Rep. & FESS for CRSWNP 6 mos prior & $\mathrm{Re}, \mathrm{Ir}, \mathrm{Gr}, \mathrm{Ps}$ & ESS & Recurrent CRS & $\mathrm{CP}$ \\
\hline 5 & 2008 & 94 & $20 / M$ & $L(E)$ & Ortho. & FESS for CRS 5 mos prior & Re,Ir,Ps & ESS & Paranasal mass & $\mathrm{CP}$ \\
\hline 6 & 2015 & 2 & $75 / M$ & $L(M)$ & Den. Rep & $\begin{array}{c}\text { Endoscopic Septoplasty } 1 \text { year } \\
\text { prior }\end{array}$ & $\mathrm{Re}, \mathrm{Ir}, \mathrm{Gr}, \mathrm{Ps}$ & ESS & $\begin{array}{c}\text { Paranasal sinus } \\
\text { PCG }\end{array}$ & ES \\
\hline 7 & 2013 & 13 & $32 / \mathrm{M}$ & L(M) & no & FESS for CRSwNP 11 mos prior & Ps & ESS & Recurrent CRS & ES \\
\hline 8 & 2015 & 12 & $30 / \mathrm{M}$ & $R(E)$ & Den. Res. & $\begin{array}{c}\text { Endoscopic removal of NPs } 9 \\
\text { mos prior }\end{array}$ & $\mathrm{Re}, \mathrm{Ir}, \mathrm{Gr}, \mathrm{Ps}$ & ESS & $\begin{array}{l}\text { Paranasal } \\
\text { foreign body }\end{array}$ & ES \\
\hline 9 & 2013 & 14 & $22 / \mathrm{M}$ & $\mathrm{L}(\mathrm{M})$ & no & FESS for CRSWNP 7 mos prior & Ps & ESS & Recurrent CRS & VG \\
\hline 10 & 2008 & 89 & $44 / F$ & $R(M)$ & Den. Res. & $\begin{array}{c}\text { Endoscopic Septoplasty } 8 \text { mos } \\
\text { prior }\end{array}$ & $\mathrm{Re}, \mathrm{Ps}$ & ESS & Paranasal mass & VG \\
\hline 11 & 2010 & 70 & $27 / F$ & $\mathrm{R}(\mathrm{MNC})$ & no & $\begin{array}{c}\text { Endoscopic Septoplasty } 4 \text { mos } \\
\text { prior }\end{array}$ & $\mathrm{Re}, \mathrm{Ir}, \mathrm{Gr}, \mathrm{Ps}$ & ESS & Foreign body & $\mathrm{CP}$ \\
\hline 12 & 2011 & 40 & $51 / \mathrm{M}$ & $\mathrm{L}(\mathrm{Sp})$ & $\begin{array}{l}\text { Root } \\
\text { canal }\end{array}$ & FESS for CRS 9 mos prior & Re,lr,Ps & ESS & Recurrent CRS & $\mathrm{CP}$ \\
\hline 13 & 2007 & 87 & $44 / \mathrm{M}$ & $R(E)$ & no & FESS for CRSWNP 4 mos prior & $\mathrm{Re}, \mathrm{Ir}, \mathrm{Gr}, \mathrm{Ps}$ & ESS & $\begin{array}{l}\text { Paranasal } \\
\text { foreign body }\end{array}$ & ES \\
\hline 14 & 2005 & 117 & $15 / F$ & $R(M)$ & no & FESS for CRS 5 mos prior & Ps & ESS & Recurrent CRS & $\mathrm{CP}$ \\
\hline 15 & 2009 & 70 & $37 / F$ & $R(M)$ & no & FESS for CRSWNP 8 mos prior & Ps & ESS & Recurrent CRS & ES \\
\hline 16 & 2011 & 37 & $19 / \mathrm{M}$ & $R(E)$ & no & FESS for CRS 9 mos prior & $\mathrm{Re}, \mathrm{Ir}, \mathrm{Gr}, \mathrm{Ps}$ & ESS & $\begin{array}{l}\text { Paranasal } \\
\text { foreign body }\end{array}$ & ES \\
\hline 17 & 2013 & 24 & $40 / M$ & $R(S p)$ & Den. Res. & $\begin{array}{l}\text { Endoscopic pituitary adenomas } \\
\text { resection } 4 \text { mos prior }\end{array}$ & $\mathrm{Re}, \mathrm{Ir}, \mathrm{Gr}, \mathrm{Ps}$ & ESS & $\begin{array}{l}\text { Nasal septum } \\
\text { mass }\end{array}$ & ADM \\
\hline 18 & 2006 & 98 & $37 / M$ & $R(M)$ & no & $\begin{array}{l}\text { Endoscopic removal of NP } 10 \\
\text { mos prior }\end{array}$ & Re,Ir,Gr,Ps & ESS & Paranasal mass & ES \\
\hline 19 & 2014 & 18 & $1 / \mathrm{M}$ & $\begin{array}{l}\text { L(NV,MM, } \\
\text { MNC) }\end{array}$ & no & $\begin{array}{c}\text { Trans-oral chopstick removal } 3 \\
\text { mos prior }\end{array}$ & Re,Ir,Gr,Ps & ESS & $\begin{array}{l}\text { Paranasal } \\
\text { foreign body }\end{array}$ & $\begin{array}{l}\text { Chop- } \\
\text { stick }\end{array}$ \\
\hline 20 & 2014 & 17 & $26 / F$ & $L(M)$ & Den. Res. & $\begin{array}{l}\text { FESS for Maxillary mucocele } 7 \\
\text { mos prior }\end{array}$ & $\mathrm{Re}, \mathrm{Gr}, \mathrm{Ps}$ & ESS & Paranasal mass & ES \\
\hline 21 & 2005 & 115 & $58 / F$ & $L(E)$ & Den. Res. & FESS for CRSWNP 3 mos prior & $\mathrm{Re}, \mathrm{Gr}, \mathrm{Ps}$ & ESS & Recurrent CRS & $C P$ \\
\hline
\end{tabular}

Abbreviations: Op, operation; Fo. Up, follow-up period; mos, months; Dental P., dental procedure; Den. Res., dental restoration; Den. Rep., dental replantation; Ortho., orthodontic anchorage procedure; $M$, male; $F$, female; $R$, right; L, left; $M$, maxillary sinus; Sp, septum; E, ethomid sinus; NV, nasal vestibule; MM, middle meatus; MNC, meatus nasi communis; ESS, endoscopic sinus surgery; Re, reddish; Ir, irregular surfaced; Gr, granular-like; Ps, pus; CRSwNP, chronic rhinosinusitis with nasal polyp; CRS, chronic rhinosinusitis; NP, nasal polyp; PCG, plasma cell granuloma; ADM, artificial dura matter; $\mathrm{CP}$, cotton pledget; $\mathrm{ES}$, expandable sponge; $\mathrm{VG}$, vaseline gauze.

\section{Results}

\section{Past medical histories}

Among the 21 patients, the most common past nasal operations were functional endoscopic sinus surgery (FESS) for chronic rhinosinusitis with nasal polyps (CRSwNP) (6/21, 28.6\%), followed by FESS for chronic rhinosinusitis (CRS) (4/21, 19.0\%),
FESS for nasal polyps (NP) (3/21, 14.3\%), endoscopic septoplasty (4/21, 19.0\%), endoscopic chordoma resection (1/21, 4.8\%), endoscopic pituitary adenoma resection (1/21, $4.8 \%)$, and FESS for maxillary mucocele $(1 / 21,4.8 \%)$. There was also one case of transoral chopstick removal. Three patients underwent a dental procedure on the lesion side of the maxilla. 


\section{Clinical symptoms}

The most common presenting symptom was mucopurulent discharge (19/21, 90.5\%), followed by epistaxis (17/21, 80.9\%), headache (10/21, 47.6\%), nasal obstruction (10/21, 47.6\%), and postnasal drip (2/21,9.5\%). These symptoms are nonspecific and could be caused by many other paranasal diseases.

\section{Initial diagnosis and endoscopic findings}

Of the 21 preoperative diagnoses, 15 were incorrect. Initial diagnoses included paranasal plasma cell granuloma, recurrent disease, and paranasal mass. Nasal endoscopy showed that the paranasal gossypiboma was reddish, granular-like (13/21), and usually covered with pus (20/21) (Figure 1A).

\section{Radiologic findings}

Paranasal CT scans were performed in five patients. Gossypiboma appears on CT as a well-defined mass of heterogeneous internal density. In three cases, the gossypiboma manifested as a cystic lesion with a thin "calcified shell" (Figure 1C). Paranasal magnetic resonance imaging (MRI), performed in one patient, showed a heterogeneously strongly enhanced lesion in the maxilla (Figure 1D). The enhancement was frond-like and had an irregular, conglomerated shape that was separated from the normal surrounding maxillary sinus.

\section{Involved sites}

In our 21 paranasal gossypiboma cases, the sites most frequently involved were the maxillary sinus $(10 / 21,47.6 \%)$, ethmoid sinus $(6 / 21,28.6 \%)$, and nasal septum $(3 / 21,14.3 \%)$. There was also one case in which the vestibule, middle meatus, and meatus nasi communis were involved.

\section{Treatment outcomes}

There were no recurrences during the mean 52-month follow-up (Figure 1B). There were also no surgical complications or residual symptoms. The retained foreign bodies that caused gossypiboma were pieces of a nasal sponge $(9 / 21,42.9 \%)$, cotton pledgets (7/21, 33.3\%), Vaseline gauze (2/21, 9.5\%), artificial dura matter $(2 / 21,9.5 \%)$ and a piece of bamboo chopstick (1/21, $4.8 \%)$.

\section{Discussion}

Gossypiboma, also called "texiloma" and "gauzoma," is a cotton matrix left behind following surgery. The word gossypiboma is derived from the Latin word gossypium, meaning cotton, and the Kiswahili word boma, meaning place of concealment ${ }^{(4,5)}$. The first case of gossypiboma was reported by Wilson in $1884^{(6)}$. Because of the legal and ethical issues associated with it, little literature is available. Whatever studies are available have indicated that the main sites of involvement are the abdomen $(1 / 1000$ to $1 / 1500$ abdominal operations), pelvis, and thorax ${ }^{(2,3)}$. It has been reported to have adverse effects on virtually every major

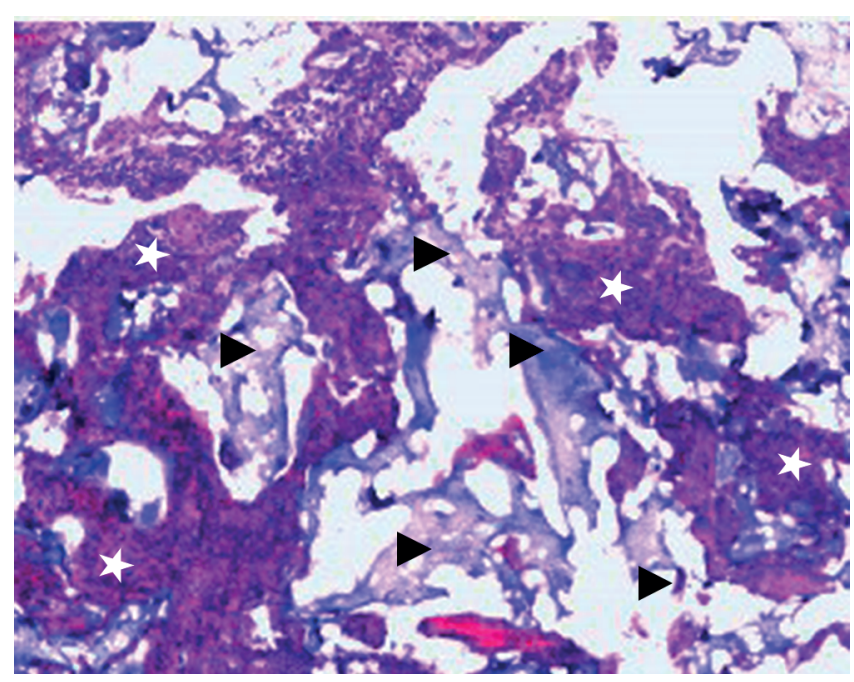

Figure 2. Histology of the gross specimen from case 6. Histologic investigation showed a core of degenerating cotton fibers (solid black arrowheads) surrounded by an inflammatory reaction (solid white star) that includes neutrophils, plasma cells, giant cells, collagen deposition, reactive vascular proliferation, and fibroblastic proliferation (hematoxylineosin stain).

body organ, including the bowel, heart, kidney, breast, urethra, bladder, uterus, and ovary ${ }^{(7-16)}$. To the best of our knowledge, no paranasal gossypibomas have been reported to date. Because of its rarity and nonspecific clinical, endoscopic, and imaging findings, paranasal sinus gossypiboma poses a diagnostic challenge.

Theoretically, there are two pathophysiological foreign body reactions around gossypibomas in other body cavities ${ }^{(17)}$. The most common is an aseptic fibrous inflammatory reaction, with adhesion that encapsulates the gossypiboma in surrounding organs. The other is an exudative inflammatory reaction, leading to a fistula or abscess ${ }^{(18,19)}$. Because of its special anatomic site, paranasal gossypiboma forms a mixed fibrous and exudative inflammatory reaction. Stuffing material is entrapped by swollen mucosa in the paranasal sinuses and is then gradually encapsulated by granular tissue. Then, being blocked by this nonresorbable nasal stuffing material and poor ventilation, the paranasal sinus fails to self-clean and thus becomes infected. The pressure exerted by the stuffing material and the accumulating pus can force it through a new opening or a natural ostium into the nasal fossa proper ${ }^{(20,21)}$.

The term gossypiboma includes all categories of nonresorbable hemostatic agent. During nasal surgery, nonresorbable materials include various forms of the cotton pledget and cloth and synthetic polyvinyl acetate hemostats (nasal sponges). Hematoxylin-eosin (H\&E) staining ${ }^{(22,23)}$ has been used to identify gossypibomas (Figure 2). Histologic examination of a gossypibo- 
ma typically shows a core of degenerating hemostatic agent surrounded by an inflammatory reaction that includes giant cells, granulomas, collagen deposition, reactive vascular proliferation, and fibroblastic proliferation ${ }^{(4)}$. Fibers from cotton pledgets are characteristically identified by their hollow, cylindrical profiles under H\&E staining ${ }^{(24,25)}$.

The most frequent symptoms of the paranasal gossypiboma are mucopurulent discharge and epistaxis, which are thought to result from mucosal irritation and exudative effects of the mass. This process may occur over months to years. Without awareness of paranasal gossypibomas, the nonspecific clinical presentation can lead to an incorrect preoperative diagnosis and unnecessary anxiety.

Various radiological techniques help diagnose gossypiboma. The most commonly retained foreign body in general surgery is the laparotomy sponge, which could be easily diagnosed by its radiopaque appearance ${ }^{(26)}$. It appears on plain radiography as a mass of soft tissue density with curved radiopaque lines. However, cotton pledges, surgical pads, and expandable sponges that are not radiopaque are widely used during endoscopic nasal surgery in hospitals worldwide, providing a challenge to imaging. In such cases, CT becomes the choice for investigation. On $C T$, a gossypiboma in other body cavities may manifest as a cystic lesion with a hyper-dense capsule with concentric layering or with an internal "spongiform" appearance with mottled gas bubbles ${ }^{(27)}$. Another CT imaging appearance, described by Lu et al. ${ }^{(28)}$, was as a "calcified reticulate rind," where the gossypiboma manifested as a cystic lesion with a calcified reticulated capsule. They attributed the appearance to two decades of calcium being deposited along the surgical sponge.

None of our five patients exhibited the abovementioned conventional imaging findings of gossypiboma, such as the radiopaque markers and the spongiform pattern with entrapped air bubbles. One possible explanation is that cotton pledges without radiopaque markers were used while the air bubbles were being completely expelled from the sinus, which, unlike peritoneal or other body cavities, communicates with the outside through natural openings. One of our patients had a cystic lesion with a thin "calcified shell," an imaging feature of gossypiboma that was probably formed by deposition of calcification around the cotton pledgets. Probably as a result of ventilation and evaporation, the process of calcification occurs faster in the paranasal sinus ( 1 year in our case) than in other body cavities (20 years in the patient described by Lu et al. ${ }^{(28)}$ ). Also, unlike the reticular form described by Lu et al., calcification produces a complete "shell" that enwraps the entire foreign body. When a patient with a history of nasal surgery presents this CT picture, especially in the maxillary or ethmoid sinus, gossypiboma should be kept in mind.

Rhinoliths and rhinolithiasis are conditions with which the otolaryngologist should be familiar, as they manifest as a mineralized mass in the nasal cavity ${ }^{(29)}$. Unlike paranasal gossypibomas, which are composed of retained surgical gauze surrounded by an inflammatory reaction, a rhinolith consists of a kernel that has undergone calcification, resulting in hard, grayish, calcareous concretions within the nasal cavity ${ }^{(30,31)}$. Whereas a paranasal gossypiboma is caused solely by artificial surgical materials, a rhinolith can be triggered by any exogenous object (e.g., buttons, beads, fruit seeds, pebbles, sand, cotton, paper) or endogenous material (e.g., a blood clot, epithelial debris, teeth, dried pus, nasal secretions, osseous fragments). Unlike paranasal gossypibomas, which are always preceded by documented endoscopic nasal surgery ${ }^{(32)}$, most patients with a rhinolith could not remember entrance of a foreign body. The longest residing asymptomatic rhinolith known was present for 80 years ${ }^{(33)}$. Because of its troublesome symptoms (e.g., epistasis, nasal obstruction, headache), typically it is only months before patients with a paranasal gossypiboma seek medical help.

Whereas paranasal gossypibomas are usually diagnosed by otorhinolaryngologists via CT and intraoperative findings, rhinoliths are most often diagnosed incidentally by dentists ${ }^{(34,35)}$. Dental radiographs, such as periapical films or panoramic tomograms, partially show the floor of the nose, where rhinoliths are most often found ${ }^{(36,37)}$. Radiographically, rhinoliths characteristically appear to be of heterogeneous density with a corrugated radiopaque border ${ }^{(38)}$. On $\mathrm{CT}$, the rhinolith appears as a densely calcified mass with a much thicker and denser calcified rim and a residual soft tissue core compared with the paranasal gossypiboma, which is a cystic lesion with a thin "calcified shell." Whereas paranasal gossypibomas are soft, irregular, reddish, granular-like, and nonspecific viewed under endoscopy, rhinoliths are easily identified as irregular, porous, hard, grayish to blackish masses along the nasal floor ${ }^{(39)}$.

Overall, retention of a foreign body in the nasal cavity is rare. The incidence was $0.36 \%$ in our hospital from 2005 to 2015 . Theoretically, it is unlikely that the surgeon could leave the nasal stuffing material in the cavity unnoticed because we are able to see the nasal cavity at the completion of an endoscopic sinus operation. However, there is great uncertainty about why these incidents occur and how to prevent them. By reviewing 21 cases, we summarized a few possible risk factors for paranasal gossypiboma.

Compared with published articles ${ }^{(2,3)}$, our incidence of $0.36 \%$ is high, especially for a tertiary hospital. In fact, 20 of our 21 patients (95\%) had undergone their prior nasal surgery in primary hospitals and clinics. Thus, taking into account the amount of 
nasal surgery performed in primary hospitals, the incidence should be much lower than $0.36 \%$. According to Gawande et al. ${ }^{(40)}$, counts of sponge and instruments are significantly associated with an increased risk of foreign body retention. In the present study, the most frequent sites of paranasal gossypiboma were the maxillary and ethmoid sinuses (10 and 6 cases, respectively), and the most frequent responsible surgeries were FESS for CRSWNP, CRS, and NP. These most basic, simple procedures are readily accessible to many primary hospitals and clinics, where time-out protocols, surgery safety systems, supervisory systems, and standards for patient safety are weak or even absent ${ }^{(41)}$. Moreover, although endoscopy provides an unobstructed view of the nasal cavity, a clear surgical field achieved with proper hemostasis is a precondition for accurate judgment. Premedication, intraoperative blood pressure control, surgical positioning, a local anesthetic, and adequate surgical skill are the significantly relevant factors for surgical field control ${ }^{(42)}$. Without sufficient staff, standards, knowledge, or equipment, even basic FESS in a primary hospital could result in grade $4 / 5$ bleeding ${ }^{(43)}$ and emergent packing, which is another risk factor for foreign body retention according to Gawande et al. ${ }^{(40)}$.

With only three of our patients having undergone dental procedures on the lesion side of the maxilla, dental procedures seem unlikely to be the subject of liability in our study. Dental procedures, however, are still a possible cause of paranasal gossypiboma ${ }^{(44)}$. These foreign bodies may enter the maxillary sinus through an oro-antral fistula, which is formed by a break in the bony segment of the maxillary sinus floor following maxillary premolar and molar extractions ${ }^{(45)}$.

Although human mistakes cannot be completely avoided, strict adherence to rules and continuous medical training should greatly reduce the incidence of gossypibomas. Three factors should be mentioned: 1) A quiet, highly organized operating room provides surgical staff with the optimal environment for concentration, and two or three sponge counts should be done (46). 2) In addition to careful counting, systemically arranged postoperative follow-up could shorten the time needed to detect the missed removal of a sponge. 3) Extra caution should be taken to identify any possible retained foreign body during surgery in patients with a past history of nasal surgery.

\section{Conclusion}

Our study determined that patients who present with a single cystic mass having a thin "calcified shell" on CT imaging and a positive nasal surgery history were at higher risk for harboring a paranasal gossypiboma. Paranasal gossypibomas should definitely be considered in the differential diagnosis when surgery had been performed at a primary hospital. Detailed history-taking along with awareness of the characteristic clinical and imaging manifestations are critical for accurate diagnosis of a gossypiboma.

\section{Acknowledgements}

This study was supported by grant 2010004 from the Sun Yatsen University 5010 Plan.

\section{Authorship contribution}

All authors make major contributions to design, and/or acquisition of data, and/or interpretation and analysis of data. All authors give final approval of the version to be submitted.

\section{Conflict of interest}

None

\section{References}

1. Suwatanapongched T, Boonkasem S, Sathianpitayakul E, Leelachaikul P. Intrathoracic gossypiboma: radiographic and CT findings. Br J Radiol 2005; 78: 851 853.

2. Koul PA, Mufti SA, Khan UH, Jan RA Intrathoracic gossypiboma causing intractable cough. Interact Cardiovasc Thorac Surg 2012; 14: 228-230.

3. Gibbs VC, Coakley FD, Reines HD. Preventable errors in the operating room retained foreign bodies after surgery. Curr Probl Surg 2007; 44: 281-337.

4. Ribalta T, McCutcheon IE, Neto AG, et al. Textiloma (gossypiboma) mimicking recurrent intracranial tumor. Arch Pathol Lab Med. 2004 Jul; 128(7): 749-58.

5. Jain M, Jain R, Sawhney S. Gossypiboma: ultrasound-guided removal. J Clin Ultrasound. 1995 Jun; 23(5): 321-3.
6. Lauwers PR, Van Hee RH. Intraperitoneal gossypibomas: the need to count sponges. World J Surg. 2000 May; 24(5): 521-7.

7. Solaini L, Prusciano F, Bagioni P. Intrathoracic gossypiboma: a movable body within a pseudocystic mass. Eur J Cardiothorac Surg. 2003; 24: 300.

8. Malempre D, Boverie J, Trotteur G. Retroperitoneal textiloma. J Belge Radiol. 1989; 72: 522-523.

9. Lo CP, Hsu CC, Chang TH. Gossypiboma of the leg: MR imaging characteristics. Korean J Radiol. 2003; 4: 191-193.

10. Kalbermatten DF, Kalbermatten NT, Hertel R. Cotton-induced pseudotumor of the femur. Skeletal Radiol. 2001; 30: 415-417

11. Gencosmanoglu R, Inceoglu R. An unusual cause of small bowel obstruction: gossypiboma-case report. BMC Surg. 2003; 3: 6.

12. El Koury M, Mignon F, Tardivon A, Mesurolle B, Rochard F, Mathieu MC. Retained surgical sponge or gossypiboma of the breast. Eur $J$ Radiol. 2002; 42: 58-61.

13. Bhat HS, Mahesh G, Ramgopal KS "Gossypiboma": an unusual cause of perinephric abscess. J R Coll Surg Edinb. 1997; 42: 277-278.

14. Lin TY, Chuang CK, Wong YC, Liao HC. Gossypiboma: migration of retained surgical gauze and spontaneous transurethral protrusion. BJU Int. 1999; 84: 879-880.

15. Lerner CA, Dang HP. MR imaging of a pericardial gossypiboma. Am J Roentgenol. 1997; 169: 314.

16. Fadiora SO, Komolafe JO, Ogunniyi SO. Gossypiboma simulating huge ovarian mass: a case report. Niger J Med. 2003; 12: 52-56.

17. Sakorafas $G H$, Sampanis D, Lappas C, P, et al. Retained surgical sponges: what the practicing clinician should know. Langenbecks Arch Surg. 2010 Nov; 395(8): 1001-7. 
18. Yildirim S, Tarim A, Nursal TZ et al (2006) Retained surgical sponge (gossypiboma) after intraabdominal or retroperitoneal surgery: 14 cases treated at a single center. Langenbecks Arch Surg 391: 390-395.

19. Sturdy JH, Baird RM, Gerein AN (1967) Surgical sponges: a cause of granuloma and adhesion formation. Ann Surg 165: 128-134.

20. Godara R, Marwah S, Karwasra RK, Goel R, Sen J, Singh R. Spontaneous transmural migration of surgical sponges. Asian J Surg. 2006 Jan;29(1): 44-5.

21. Kaiser CW, Friedman S, Spurling KP, Slowick T, Kaiser HA. The retained surgical sponge. Ann Surg. 1996 Jul; 224(1): 79-84.

22. Aydogan M, Mirzanli C, Ganiyusufoglu K, Tezer M, Ozturk I. A 13-year-old textiloma (gossypiboma) after discectomy for lumbar disc herniation: a case report and review of the literature. Spine J. 2007 Sep-Oct; 7(5): 618-21.

23. Sigron GR, Locher MC. A gossypiboma (foreign body granuloma) mimicking a residual odontogenic cyst in the mandible: a case report. J Med Case Rep. 2011 May 28; 5: 211.

24. Fitzgerald LF, Goodman JC. Microscopic appearance of iatrogenic foreign bodies in neurosurgery. Clin Neuropathol. 1999; 18: 307-310.

25. Alves-de-Oliveira CN, Pimenta-do-Amaral TM, Ribeiro-Souto G, Alves-Mesquita R. Gossypiboma in the oral region: Case report and literature review. J Clin Exp Dent. 2014 Oct 1; 6(4): e444-7.

26. Williams RG, Bragg DG, Nelson JA. Gossypiboma-the problem of the retained surgical sponge. Radiology 1978; 129: 323-326.

27. Kopka L, Fischer U, Gross AJ, Funke M, Oestmann JW, Grabbe E. CT of retained surgical sponges (textilomas): pitfalls in detection and evaluation. J Comput Assist Tomogr. 1996 Nov-Dec; 20(6): 919-23.

28. Lu YY, Cheung YC, Ko SF, Ng SH. Calcified reticulate rind sign: a characteristic feature of gossypiboma on computed tomography. World I Gastroenterol. 2005 Aug 21; 11(31): 4927-9.

29. Pinto LS, Campagnoli EB, de Souza Azevedo R, Lopes MA, Jorge J. Rhinoliths causing palatal perforation: case report and literature review. Oral Surg Oral Med Oral Pathol Oral Radiol Endod. 2007 Dec; 104(6): e42-6.

30. Appleton SS, Kimbrough RE, Engstrom HI. Rhinolithiasis: a review. Oral Surg Oral Med Oral Pathol Oral Radiol Endod 1988; 65: 6938.

31. Wickham MH, Barton RP. Nasal regurgitation as the presenting symptom of rhinolithiasis. J Laryngol Otol 1988; 102: 59-61.

32. Aksungur EH, Binokay FB, Biçakçi K, Apaydin $D$, Oğuz $M$, Aydoğan B. A rhinolith which is mimicking a nasal benign tumor. Eur Radiol. 1999 Jul; 31 (1): 53-5.

33. M.S. Kermanshahi, P. Jassar, A bolt from the blew: rhinolith in the nose for than 80 years, BMJ Case Rep. 2012 Nov 27; 2012.

34. Ruprecht A, Wang CM, Rak D. Unsuspected rhinolith. Dent J. 1979 Mar; 45(3): 116-7.

35. Allen GA, Liston SL. Rhinolith: unusual appearance on panoramic radiograph. $J$ Oral Surg. 1979 Jan; 37(1): 54-5.

36. Damm DD, Ziegler RC. Factitious rhinolith Oral Surg Oral Med Oral Pathol. 1985 Jun; 59(6): 662.

37. Marano PD, Smart EA, Kolodny SC. Rhinolith simulating osseous lesion: report of case. $J$ Oral Surg. 1970 Aug; 28(8): 615-6.

38. Birrell JF, ed. Logan Turner's diseases of the nose, throat, and ear. 9th ed. Bristol: John Wright \& Sons, 1982: 46-7.

39. Hadi U, Ghossaini S, Zaytoun G. Rhinolithiasis: A forgotten entity. Otolaryngol Head Neck Surg. 2002 Jan: 126(1): 48-51

40. Gawande AA, Studdert DM, Orav EJ, Brennan TA, Zinner MJ. Risk factors for retained instruments and sponges after surgery. N Engl J Med. 2003 Jan 16; 348(3): 229-35.

41. Stefl ME. To err is human: building a safer health system in 1999. Front Health Serv Manage. 2001 Fall; 18(1): 1-2.

42. Khosla AJ, Pernas FG, Maeso PA. Metaanalysis and literature review of techniques to achieve hemostasis in endoscopic sinus surgery. Int Forum Allergy Rhinol. 2013 Jun; 3(6): 482-7.

43. Boezaart AP, van der Merwe J, Coetzee A (1995) Comparison of sodium nitroprusside- and esmolol-induced controlled hypotension for functional endoscopic sinus surgery. Can J Anaesth 42: 373-376.

44. González-García A, González-García J, Diniz-Freitas M, García-García A, Bullón P. Accidental displacement and migration of endosseous implants into adjacent craniofacial structures: a review and update. Med Oral Patol Oral Cir Bucal. 2012 Sep 1;17(5): e769-74.

45. Deniz Y, Zengin AZ, Karli R. An unusual foreign body in the maxillary sinus: Dental impression material. Niger J Clin Pract. 2016 Mar-Apr; 19(2):298-300

46. Sandrasegaran K, Lall C, Rajesh A, Maglinte DT. Distinguishing gelatin bioabsorbable sponge and postoperative abdominal abscess on CT. AJR Am J Roentgenol. 2005 Feb; 184(2): 475-80.

Prof. Dr. Wei-Ping Wen

Department of Otorhinolaryngology

The First Affiliated Hospital

Otorhinolaryngology Institute

Sun Yat-sen University

No. 58 Second Zhongshan Rd

Guangzhou 510080

People's Republic of China

Tel: +8613802966937

E-mail:wenwp@mail.sysu.edu.cn 